\title{
CORRESPONDENCE
}

\section{Microstructures in titanomagnetite: discussion of a paper by G. D. Price}

SIR - In a recent paper Price (1979) described a mottled texture observed in electron micrographs of a magnetite ${ }_{s s}-$ ulvöspinel ${ }_{s s}$ exsolution intergrowth. The mottled texture was restricted to the magnetite-rich component of the intergrowth, and was attributed to a second stage of exsolution within this phase, the transformation having taken place by the mechanism of spinodal decomposition. Although spinodal decomposition is a likely mechanism for exsolution in this system, owing to the similar structures and unit cell parameters of the end members, it seems probable that the structure described by Price is an artefact produced in the laboratory during ion-beam thinning of the material. This is an attempt to justify this point of view.

In the recent literature there have been a number of examples of the same texture in spinels prepared for electron microscopy by ion-beam bombardment. The published examples include spinels of a considerable variety of compositions. Smith $(1979 a)$ illustrated this texture in a titanomagnetite containing about $60 \%$ of the ulvöspinel component, and also reported that a magnesium-aluminium spinel showed the same texture when ion-thinned, but that samples of the same spinel prepared by crushing did not show the texture. Thus the mottled texture was considered to arise during ion-thinning. Putnis (1979) reported the same texture in magnetite found as an oxidation product of olivine. The magnetite was thought to be pure $\mathrm{Fe}_{3} \mathrm{O}_{4}$, with possible substitution of magnesium for iron. Putnis also stated that he had observed the same texture in chrome spinels, and that G. D. Price (quoted as a personal communication) found the texture to be typical of magnetites. Smith (1979b) also showed this texture in a pure magnetite $(<0.5$ atom \% Ti). All the cited examples of this texture involve ion-beam thinned specimens.

Surely the simplest conclusion to be drawn from these reported observations is that the mottled texture is common to spinels of all compositions, and that it is formed during ion-beam thinning. The texture is in fact very similar in appearance to that illustrated by Mazey, Nelson \& Barnes (1968) for silicon damaged by ion-bombardment. If this texture is indeed an artefact, Price is wrong in attributing it to fine-scale exsolution, and his deduction concerning the cooling rate of the rock is invalid.

A further point of interest that arises from Price's paper is that the ulvöspinel-rich component of the intergrowth described does not show the mottled texture (Plate 1 B, C). In my view this fact su ggests that this phase is ilmenite, formed by oxidation-exsolution, rather than ulvöspinel. If this is the case the lamellae must lie on $\{111\}$, the usual orientation for an exsolved rhombahedral phase in magnetite, rather than $\{100\}$. This might at first seem to be in conflict with the near right-angle between the two orientations of these lamellae in Price's micrographs, but it should be noted that a $\{111\}$ intergrowth will also show two perpendicular traces in a [100] section. If the unmottled phase is ilmenite then the precipitate phase seen within it in Plate $1 \mathrm{~B}$ could perhaps be rutile, formed by further oxidation. The splitting of the diffraction spots in Plate $1 \mathrm{D}$ does not appear to be consistent with Price's model of a magnetite ${ }_{\mathrm{ss}}-\mathrm{ulvöspinel}_{\mathrm{ss}}$ intergrowth, as lines joining the paired reflections do not converge on the $(000)$ spot as they should for the simple case of two cubic phases in the same orientation but with differing cell parameters. It may be that Price has further diffraction evidence to support his view, in which case his observations would provide an interesting example of a spinel phase that does not show a mottled texture when thinned by ion-beam bombardment.

\section{References}

Mazey, D. J., Nelson, R. S. \& Barnes, R. S. 1968. Observation of ion bombardment damage in silicon. Phil. Mag. 17, 1145-61.

Price, G. D. 1979. Microstructures in titanomagnetites as guides to cooling rates of a Swedish intrusion. Geol. Mag. 116, 313-8.

Putnis, A. 1979. Electron petrography of high-temperature oxidation in olivine from the Rhum Layered Intrusion. Mineral. Mag. 43, 293-6. 
Smith, P. P. K. 1979(a). The identification of single-domain titanomagnetite particles by means of transmission electron microscopy. Can. J. Earth Sci. 16, 375-9.

Smith, P. P. K. $1979(b)$. The observation of enantiomorphous domains in a natural maghemite. Contrib. Mineral. Petrol. 69, 249-54.

Department of Geology

P. P. K. SMITH

Arizona State University

Tempe

Arizona 85281

U.S.A.

18th September, 1979

SIR - Transmission electron microscopy (TEM) of titanomagnetites from the Taberg intrusion (Price, 1979) reveals the presence of a lamellar phase, and magnetite-enriched blocks. The magnetite-enriched phase shows a strongly mottled contrast, while the lamellar phase is free of such contrast. In his letter Dr Smith suggests that the lamellar phase is ilmenite, and that the mottling of the magnetite-enriched blocks is purely an artefact of the ion-beam thinning, used in the sample preparation.

I, however, had originally stated (Price, 1979) that the lamellar phase is ulvöspinet-enriched, and that the mottling shown by the magnetite-enriched blocks is the result of chemical inhomogeneity. These two points must therefore be discussed further.

\section{(a) The nature of the lamellar phase}

Reflected-light microscopy of the Taberg titanomagnetites, shows that they are composed of an ulvöspinel-magnetite intergrowth, with rarer pleon aste and ilmenite lamellae. Ulvöspinel lamellae are found on $\{100\}$ of the spinel structure (parallel to the pleonaste lamellae), while ilmenite lamellae only occur on $\{111\}$. The lamellar phase, studied by TEM (Price, 1979), can be shown to lie on $\{100\}$ by simple trace analysis with its diffraction pattern. This, coupled with analytical electron microscopy (Price, 1980), proves, beyond reasonable doubt, that the lamellar phase is indeed ulvöspinel, and not, as suggested by Smith (1980), ilmenite.

\section{(b) The origin of mottled contrast in ion-beam thinned spinels}

Several TEM studies of spinel oxides have recently been performed (e.g. Putnis (1979), Smith (1979), Mishra \& Thomas (1979), and Putnis \& Price (1979)). Generally, these spinels have been prepared for TEM observation by ion-beam thinning, because spinel has no cleavage and hence the formation of suitable crushed grains is difficult. Many ion-beam thinned spinels have been reported to exhibit a fine-scale mottling $(\sim 20-50 \AA)$. However, this phenomenon is not characteristic of all spinels, in particular no mottling has been found in ulvöspinel (Price, 1979), or in the spinel polymorph of $\mathrm{Mg}_{2} \mathrm{SiO}_{4}$ (Putnis \& Price, 1979).

As pointed out by Smith (1980), there is little doubt that mottling is produced during the ion thinning process, since many samples, when viewed in crushed grain form, exhibit little fine-scale contrast, yet show a strong mottled contrast after thinning. However, I suggest that Smith (1980) is mistaken to discount the mottling produced by ion-beam thinning, as having no significance, or bearing on the structural state of the spinels. I suggest that the mottling, produced by thinning, reflects some fine-scale, or incipient, structural inhomogeneity in the material in which it is developed. The processes by which mottling can develop, and the causes of fine-scale inhomogeneity will be discussed below.

Ion-beam thinning is known to produce morphological artefacts as a result of sputtering (Barber et al. 1973). These frequently take the form of hummocks or dunes, arranged periodically, with a wavelength of $\sim 1 \mu \mathrm{m}$. The development of finer scale $(<100 \AA)$ microstructures, similar to those seen in the Taberg titanomagnetites, have also been observed. Barber (1972) found fine-scale microstructures, associated with impurity-doped aluminas. The impure aluminas exhibited 'delicate surface features', while the pure aluminas showed no fine-scale contrast. Barber (1972) suggested that the sputtering process revealed small, local variations in the impurity concentration.

A similar example of the enhancement of contrast by ion-beam thinning comes from chromites in the Rhum intrusion. Plate $1(a)$ shows a crushed grain of chromite in which a fine-scaled mottled 
microstructure is developed. The exact cause of the microstructure is not known, but it may be associated with incipient chemical or structural changes, some of which will be discussed below. Ion-beam thinning of chromite from the same sample, produced a microstructure shown in Plate $1(b)$. Here, ion-beam thinning can be seen to have intensified the inhomogeneity in the chromite. These observations support the conclusion that ion-beam thinning may reveal or enhance local inhomogeneities, which may not necessarily be visible in the bulk specimen, or in samples prepared by crushing. These fine-scaled microstructures should not, therefore, be dismissed as artefacts of ion-beam thinning, but should perhaps be considered to be microstructures enhanced by preferential etching.

There are several possible causes for the development of inhomogeneities, which could be preferably etched, or enhanced, by ion-beam thinning. Exsolution due to the low temperature breakdown of a spinel solid solution may occur by spinodal decomposition, which will involve the clustering of like cationic species. At low temperatures the kinetics of unmixing would be such as to prevent unmixing on a large scale, and inhomogeneities on the scale of only $20-50 \AA$ would be expected. Ion-beam thinning would enhance this inhomogeneity to produce a mottled microstructure. I suggest that this is the cause of the mottling seen in the Taberg titanomagnetites. The development of satellite reflections in the diffraction patterns of the titanomagnetites is also indicative of a structural modulation, which would be produced in the early stages of spinodal decomposition.

In addition to exsolution, other phenomena that could lead to inhomogeneities, and hence mottling, include ordering and structural changes. Ordering is known to occur in several spinels (e.g. $\gamma-\mathrm{Fe}_{2} \mathrm{O}_{3}$ ), and if developed on a fine scale produces a mottled microstructure (Warlimont, 1972). In addition, Grimes (1972) and others have suggested that many spinels have the space-group Fd3m only at high temperatures, and that at lower temperatures the space group of spinel is $\mathbf{F} \overline{\mathbf{4}} 3 \mathrm{~m}$. Although this suggestion is still hotly debated, it is likely that if a spinel were undergoing a low-temperature structural change, ion-beam thinning would enhance any existing structural inhomogeneities.

I therefore conclude that mottling is generally produced by ion-beam thinning. The mottling thus produced, however, is a reflection of some real structural or chemical inhomogeneity, and not simply an artefact to be ignored.

\section{References additional to above}

Barber, D. J. 1972. The preparation of thin foils of ceramics and geological materials by sputteretching. Beitr. elektronenmikroskop. Direktabb. Oberft. 5, 585-96.

Barber, D. J., Frank, F. C., Moss, M., Steeds, J. W. \& Tsong, I. S. T. 1973. Prediction of ionbombarded surface topographics using Frank's kinematic theory of crystal dissolution. J. Mat. Sci. 8, $1030-40$.

Grimes, N. W. 1972. 'Off-centre' ions in compounds with the spinel structure. Phil. Mag. 26, 1217-26.

Mishra, R. K. \& Thomas, G. 1979. Electron microscopy of ferrites. J. Am. Ceram. Soc. 62, 293-7.

Price, G. D. 1980. Exsolution microstructures in titanomagnetites, and their magnetic significance. (In preparation).

Putnis, A. \& Price, G. D. 1979. High-pressure (Mg, Fe) SiO phases in the Tenham chondritic meteorite. Nature, Lond. 280, 217-18.

Smith, P. P. K. 1979. The identification of single-domain titanomagnetite particles by means of transmission electron microscopy. Can. J. Earth Sci. 16, 375-9.

Warlimont, H. 1972. Transformations involving coherent phases and effects on mechanical properties of alloys. In Electron Microscopy and Structure of Materials (ed. G. Thomas). Berkeley: University of Calif. Press.

Department of Mineralogy and Petrology

University of Cambridge

Downing Place

Cambridge CB2 5EW

7th December, 1979 


\section{EXPLANATION OF PLATE}

Plate 1 (a). An electron micrograph (courtesy of Dr A. Putnis) of a crushed grain of chromite from the Rhum layered intrusion. The grain has developed weak mottling.

Plate $1(b)$. An electron micrograph (courtesy of Dr A. Putnis) of an ion-beam thinned grain of chromite, from the same specimen as that in Plate $1(a)$. The ion-beam thinning has accentuated the mottled texture. 
Geol. Mag. Vol. 117, 1980, Price, Plate 1, facing page 388.
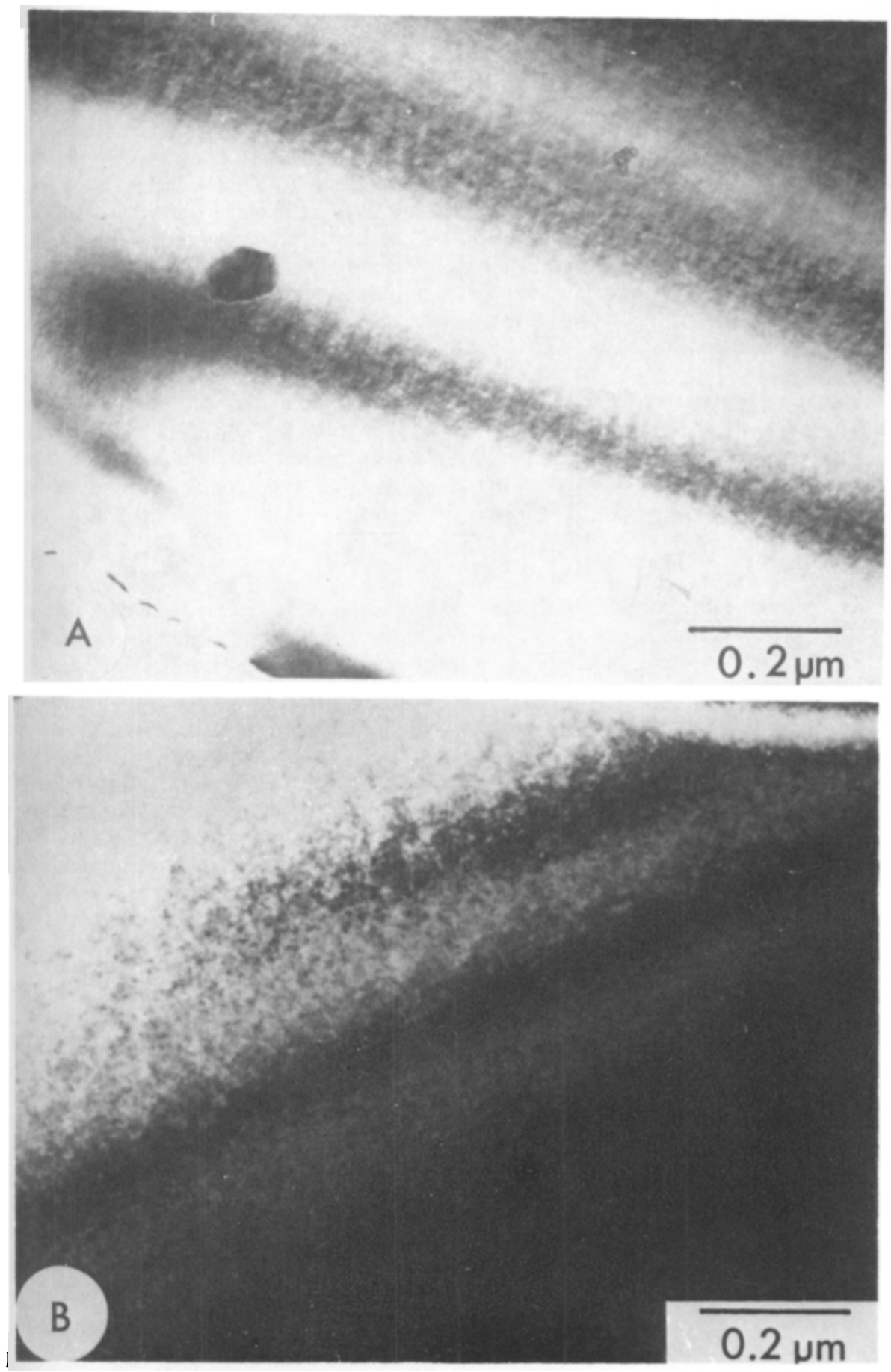